\title{
EL ALCANCE DEL PRINCIPIO NON BIS IN IDEM EN EL ÁMBITO DEL DERECHO ADMINISTRATIVO SANCIONADOR
}

THE SCOPE OF THE NON BIS IN IDEM PRINCIPLE IN THE FIELD OF ADMINISTRATIVE SANCTIONING LAW

\begin{tabular}{|c|c|}
\hline \multicolumn{2}{|c|}{ ARTÍCULO INÉDITO DE INVESTIGACIÓN } \\
\hline CÓMO CITAR ESTE ARTÍCULO (CHICAGO) & $\begin{array}{l}\text { Picón Arranz, Alberto. "El alcance del } \\
\text { principio non bis in idem en el ámbito del } \\
\text { derecho administrativo sancionador". } \\
\text { Revista de Derecho Aplicado LLM UC } 6 \\
\text { (2020). doi: 10.7764/rda.o.6.I6679. }\end{array}$ \\
\hline REVISTA DE DERECHO APLICADO LLM UC & $\begin{array}{l}\text { Número } 6 \\
\text { Diciembre } 2020 \\
\text { ISSN: } 245^{2-4344}\end{array}$ \\
\hline & $\begin{array}{l}\text { Recepción: I de julio, } 2020 \\
\text { Aceptación: } 7 \text { de agosto, } 2020\end{array}$ \\
\hline
\end{tabular}




\section{Resumen}

El objetivo del presente trabajo es analizar el alcance del principio non bis in idem en el ámbito del derecho administrativo sancionador. Para ello, estudiaremos, en primer lugar, el concepto y el fundamento del principio, así como su ubicación dentro del elenco de los derechos fundamentales. Luego, trataremos de estudiar su operatividad - tanto en su vertiente material como en la procedimental - a la luz de la prevalencia de la jurisdicción penal sobre la potestad sancionadora de la Administración. Por último, examinaremos su significación en el ámbito exclusivo del derecho administrativo sancionador.

Palabras clave: Non bis in idem, derecho administrativo sancionador, derecho penal

\section{Abstract}

The aim of this paper is to analyse the scope of the non bis in idem principle in the field of administrative sanctioning law. To this end, we will first examine the concept and basis of the principle and its place within the list of fundamental rights. Subsequently, we will try to study its operation, both in its material and procedural aspects, in light of the prevalence of criminal jurisdiction over the Administration's sanctioning power. Finally, we will examine its significance in the exclusive field of administrative sanctioning law.

Keywords: Non bis in idem, administrative sanctioning law, criminal law 


\section{Alberto Picón Arranz}

Universidad de Valladolid

Valladolid, España

alberto.picon@uva.es

Universidad de Valladolid

Valladolid, Spain

alberto.picon@uva.es
Licenciado en Derecho por la Universidad de Valladolid. Actualmente personal investigador predoctoral y profesor asociado del área de Derecho Administrativo en la Universidad de Valladolid.

Degree in Law from the University of Valladolid. Currently Predoctoral Researcher and Associate Professor of the Administrative Law Area at the University of Valladolid. 


\section{NON BIS IN IDEM Y DERECHO ADMINISTRATIVO SANCIONADOR}

A nadie se le escapa la idea de que la actividad punitiva del Estado puede llevarse a cabo tanto a través de la vía penal como de la vía administrativa. Dejando al margen discusiones doctrinales sobre la naturaleza del ius puniendi estatal - lo cual desborda con creces el objetivo del presente trabajo ${ }^{1}$, aludiremos a dos pronunciamientos del Tribunal Constitucional español y chileno, que coinciden en extrapolar los principios inspiradores del orden penal al derecho administrativo sancionador reconociendo, de manera implícita, la teoría unitaria que aboga por la idéntica naturaleza jurídica del ius puniendi del Estado.

En primer lugar, el Tribunal Constitucional español admite sin vacilaciones que "los principios inspiradores del orden penal son de aplicación, con ciertos matices, al derecho administrativo sancionador, dado que ambos son manifestaciones del ordenamiento punitivo del Estado" ${ }^{2}$. Del mismo modo, el Tribunal Constitucional chileno considera que "los principios ordenadores del orden penal contemplado en la Constitución Política de la República han de aplicarse, por regla general, al derecho administrativo sancionador, puesto que ambos son manifestaciones del ius puniendi propio del Estado" ${ }^{3}$.

A la vista de estas resoluciones, consideramos que la labor del jurista en este punto es determinar el alcance de las expresiones "con ciertos matices" y "por regla general”. El hecho de que el Poder Ejecutivo, en paralelo al Judicial, pueda ejercer la potestad sancionadora, produce una brecha en el sistema de separación de poderes. Por esto, entendemos que debe defenderse una posición especialmente garantista a la hora de trasladar "con matices" los principios del orden penal al ámbito administrativo sancionador, para evitar posibles arbitrariedades o abusos de poder en el ejercicio de la citada potestad sancionadora.

Centraremos el presente estudio en una de las garantías propias del derecho penal, que nadie duda que debe operar en el ámbito administrativo sancionador, pero cuyo fundamento, alcance y límites de operatividad son, sin embargo, motivo continuo de debate en la doctrina. Nos referimos al principio non bis in idem.

1 Se desarrolla minuciosamente la cuestión de la naturaleza jurídica del ius puniendi estatal en Manuel Gómez Tomillo e Íñigo Sanz Rubiales, Derecho administrativo sancionador: Parte general (Cizur Menor: Aranzadi, 20I7).

2 Sentencia del Tribunal Constitucional de España, rol I8/I98I, 8 de junio de I98I, fundamento jurídico 2.

3 Sentencia del Tribunal Constitucional de Chile, rol 244, 26 de agosto de I996, considerando noveno. 


\section{I.I. Alcance y límites del principio non bis in idem}

Pese a que no encontramos en los textos constitucionales de España ni de Chile la enunciación del principio non bis in idem, su vigencia en ambos ordenamientos está fuera de toda duda. Así, en el ámbito internacional, el artículo 50 de la Carta de los Derechos Fundamentales de la Unión Europea, a continuación del principio de legalidad, consagra el

derecho a no ser juzgado o condenado penalmente dos veces por la misma infracción: nadie podrá ser juzgado o condenado penalmente por una infracción respecto de la cual ya haya sido absuelto o condenado en la Unión mediante sentencia penal firme conforme a la ley.

Por su parte, el Convenio Europeo de Derechos Humanos y las Libertades Fundamentales (firmado en Roma el 4 de noviembre de 1950), en su artículo 4 del protocolo 7, que lleva por título "Derecho a no ser juzgado o condenado dos veces", dispone que

nadie podrá ser perseguido o condenado penalmente por los tribunales del mismo Estado, por una infracción por la que ya hubiera sido absuelto o condenado en virtud de sentencia firme conforme a la ley y al procedimiento penal de ese Estado.

En términos casi idénticos se pronuncian el artículo 14.7 del Pacto Internacional de Derechos Civiles y Políticos de 1966 y el artículo 8.4 de la Convención Interamericana de Derechos Humanos.

En definitiva, el principio non bis in idem consiste en la prohibición de duplicar sanciones por un mismo hecho cuando las normas sancionadoras tengan el mismo fundamento tuitivo. Se requiere para su operatividad, en definitiva, la triple identidad de sujeto, hecho y fundamento $0^{4}$. Desde la vertiente del derecho administrativo ${ }^{5}$, impide que la Administración sancione un hecho constitutivo de delito que ya haya sido sancionado en vía administrativa ${ }^{6}$ (vertiente material) o que inicie o continúe un procedimiento sancionador

4 No es objeto del presente trabajo el desarrollo del contenido de la triple identidad (hecho, sujeto y fundamento) necesaria para poder apreciar el non bis in idem. Nos remitimos en este punto al valioso análisis de José Ignacio Cubero Marcos, El principio non bis in idem en la ley vasca de la potestad sancionadora (Oñate: Instituto Vasco de Administración Pública, 20ı০), 49-92.

5 En la legislación administrativa española, el principio non bis in idem está plasmado en el artículo 3r.r de la Ley $4_{4}^{\circ} / 20$ I5 , del I de octubre, de Régimen Jurídico del Sector Público: "No podrán sancionarse los hechos que lo hayan sido penal o administrativamente, en los casos en que se aprecie identidad del sujeto, hecho y fundamento".

6 Gómez Tomillo y Sanz Rubiales, Derecho..., 2Io, 217. 
cuando esos hechos puedan constituir delito o estén siendo enjuiciados en vía penal o investigados en vía administrativa (vertiente procesal). En este punto, la vertiente procesal tiene como finalidad evitar la vulneración material del principio, que es la que en verdad se traduce en un perjuicio real para el sancionado ${ }^{7}$.

\section{I.2. Fundamento}

Si bien parece que existe unanimidad en la doctrina en reconocer tanto la vertiente material como procesal del non bis in idem, no podemos decir lo mismo respecto de su fundamento.

Un sector doctrinal considera que el fundamento de la garantía del non bis in idem reside en el principio de proporcionalidad ${ }^{8}$. Lo que trata de evitar esta garantía es la desproporción que implica imponer dos o más sanciones o juzgar dos o más veces a un sujeto por los mismos hechos. No limitar la posibilidad de sanción o enjuiciamiento cuando exista la triple identidad antes aludida conllevaría, incluso, un gran riesgo de arbitrariedad por parte del Estado en su ejercicio del ius puniendi.

Por su parte, otro sector doctrinal, sin renunciar a la relación que existe entre el principio non bis in idem y el principio de proporcionalidad, considera que el verdadero fundamento de esta garantía se encuentra en el principio de legalidad o, más en concreto, en el principio de tipicidad ${ }^{9}$. También el Tribunal Constitucional español ha señalado que el principio "va íntimamente unido a los principios de legalidad y tipicidad de las infracciones" ${ }^{10}$, con lo cual lo eleva a la categoría de derecho fundamental. En efecto, el principio

7 Además de impedir que entre dos órganos del Estado puedan darse resoluciones contradictorias y de un fundamento de pura seguridad jurídica, la vertiente procedimental "busca impedir la imposición de dos sanciones por los mismos hechos, esto es, se encuentra preordenado a garantizar el principio non bis in idem material". Manuel Gómez Tomillo, "Non bis in idem en los casos de dualidad de procedimientos penal y administrativo: Especial consideración de la jurisprudencia del TEDH", InDret 3 (2020): 425 .

8 María Magdalena Ossandón Widow, "El principio ne bis in idem en el sistema jurídico chileno: Análisis de la jurisprudencia constitucional”, Revista de Ciencias Penales $4^{2}$ (20I6): 2; Juan Pablo Mañalich, "El principio ne bis in idem frente a la superposición del derecho penal y el derecho administrativo sancionatorio", Política Criminal 9, n. ${ }^{\circ}$ I8 (20I4): $54^{8}$.

9 Íñigo Sanz Rubiales, "Potestad sancionadora administrativa, non bis in idem y primacía del orden penal (Comentarios a la STC I77/ı999, de II de octubre)”, Revista del Poder Judicial 59, (2000): 546; Gómez Tomillo y Sanz Rubiales, Derecho..., 2Ir. Vinculan absolutamente el principio non bis in idem con el principio de legalidad penal, y descartan cualquier posible vinculación con el principio de proporcionalidad.

10 Sentencia del Tribunal Constitucional de España, rol 2/ı98I, 30 de enero de ig8I, fundamento jurídico 4 . 
de tipicidad exige que el legislador prevea que la respuesta sancionadora a una conducta sea una determinada y no el cúmulo de diversas reacciones punitivas. En otras palabras, los hechos tipificados como infracciones deben ser excluyentes, no cabe la posibilidad de sancionar una conducta ya sancionada.

Al ser conscientes de la relación existente entre la prohibición del non bis in idem y el principio de proporcionalidad, no podemos considerar a este último el fundamento del primero, pues, bajo esta lógica, se podría admitir la doble sanción de unos mismos hechos cuando la primera sanción resultase demasiado leve o insuficiente. No plantea estos problemas reconocer al principio de legalidad como el fundamento del non bis in idem, ya que este implica que el legislador tipifica las infracciones penales y administrativas de forma excluyente, de manera que, una vez aplicada la norma sancionadora a unos hechos, no cabe aplicarla de nuevo para los mismos hechos y el mismo sujeto ${ }^{11}$.

\section{I.3. Las mal denominadas excepciones del principio non bis in idem}

El rango de derecho fundamental atribuido al principio non bis in idem nos obliga, aunque sea en forma somera, a aludir a dos situaciones que no pocas veces son consideradas, de manera errónea a nuestro juicio, como excepciones a la prohibición general del principio.

La primera tiene que ver con los supuestos en que concurra una relación de supremacía especial - también denominada de especial sujeción- entre la Administración ${ }^{12}$ y el sancionado. Nos referimos la imposición de sanciones administrativas, además de la penal, por parte de la Administración a quienes trabajan para ella por conductas realizadas en el marco de la relación de servicios que unen al sancionado y a la Administración. El supuesto más común en la práctica es el de imposición de sanciones disciplinarias a los funcionarios públicos.

Pues bien, no cabe admitir sin más la validez de la doble sanción sin antes comprobar que en efecto las sanciones obedecen a fundamentos diferentes. De hecho, la relación de sujeción especial no implica en forma automática un diferente fundamento punitivo penal y administrativo. En este sentido, la Sala de lo Contencioso Administrativo del Tribunal Supremo español ha considerado que "la mera existencia de una relación de sujeción es-

11 Tomás Cano Campos, "Non bis in idem, prevalencia de la vía penal y teoría de los concursos en el derecho administrativo sancionador”, Revista de Administración Pública I56 (2001): 208.

12 Cubero Marcos, El principio..., 93; Elena Blanca Marín de Espinosa Ceballos, "El principio non bis in idem: La acumulación de sanciones penales y administrativas en la protección del medio ambiente", en Derecho, globalización, riesgo y medio ambiente, ed. por Esteban Juan Pérez Alonso, Estanislao Arana García, Pedro Mercado Pacheco y José Luis Serrano Moreno (Valencia: Tirant lo Blanch, 2012), 748 . 
pecial a la Administración (como es la de los funcionarios públicos) no basta por sí misma [...] para justificar la dualidad de sanciones, penal y administrativa”, pues el Código Penal prevé un listado de delitos "propios", en los que es conditio sine qua non que el sujeto tenga una determinada condición - en este caso, funcionario público- para que se le pueda sancionar. Por ello, en ese tipo penal se encuentra incorporado ya el fundamento de la sanción administrativa, y no se podrá sancionar la conducta penal y administrativamente sin incurrir en violación del principio ${ }^{13}$.

En conclusión, el principio non bis in idem opera plenamente en el ámbito de las relaciones de sujeción especial. Lo importante será determinar en cada caso concreto si, en efecto, concurre o no el mismo fundamento en las dos sanciones (penal y administrativa), en cuyo caso se admitirá la doble sanción.

En segundo lugar, encontramos otra posible excepción a la vulneración del principio non bis in idem, basada en la inactividad del interesado que no pone en conocimiento del juez penal o de la Administración que se está siguiendo un procedimiento paralelo concurriendo la triple identidad ${ }^{14} y$, en consecuencia, se produce la doble sanción. Esta actitud pasiva del interesado, según el Tribunal Constitucional español, sería suficiente para determinar que no hay vulneración de la prohibición del bis in idem.

No podemos compartir esta posición del Alto Tribunal, pues parece contraria a la razón de ser de los derechos fundamentales. Sin duda, uno de los elementos definitorios de estos es su indisponibilidad individual, precisamente por su íntima conexión con el orden público ${ }^{15}$. Por ello, la pasividad del interesado no puede equivaler nunca a la renuncia de sus derechos fundamentales.

13 Sentencia del Tribunal Supremo español, Sala Tercera, i6 de diciembre de 2008, fundamento de derecho 3 .

14 Sentencia del Tribunal Constitucional español, rol I52/200I, 2 de julio de 200I, fundamento jurídico 2: "Deberá ser objeto de consideración especial el dato de que en la producción de dicha duplicidad ha influido de modo decisivo la actitud del recurrente, que perfectamente pudo haberlo impedido, y no lo intentó, simplemente con la alegación en el procedimiento administrativo de la simultánea pendencia del proceso penal, lo que hubiera podido determinar la suspensión del primero".

15 En contra de nuestra opinión, Alejandra Boto Álvarez, "Actos administrativos que lesionan derechos y libertades susceptibles de amparo constitucional: Análisis de la doctrina de los órganos consultivos en expedientes de revisión de oficio”, Revista Vasca de Administración Pública 96 (20I3): 6I. 


\section{LA PREVALENCIA DE LA JURISDiCCIÓN PENAL SOBRE EL DERECHO ADMINISTRATIVO SANCIONADOR}

La práctica jurídica nos ofrece múltiples situaciones que pueden analizarse a la luz del principio non bis in idem. A lo largo de las próximas líneas, trataremos de fijar criterios válidos para salvaguardar esta garantía con rango de derecho fundamental en el ejercicio del ius puniendi del Estado.

El primer criterio a tener en cuenta a la hora de analizar la prohibición del bis in idem -que, a nuestro juicio, presenta pocas dudas - es la primacía del orden penal sobre el administrativo sancionador. Los principales argumentos que se esgrimen en favor de este argumento giran en torno a las mayores garantías que tiene el proceso judicial penal frente al derecho administrativo sancionador. En efecto, si - como hemos visto al comienzo de este trabajo - los principios inspiradores del orden penal deben aplicarse "con ciertos matices" al derecho administrativo sancionador, es lógico entender que los matices consistirán casi siempre en una relajación de las garantías por la propia razón de ser de la Administración que se integra en el Poder Ejecutivo del Estado frente al juez penal. Además, la primacía del orden penal se basa también en su configuración como ultima ratio reservada a las conductas más reprochables y que conllevan sanciones más graves, lo cual lleva implícito un despliegue mayor de garantías que provoca, en caso de acumulación de un proceso penal con un administrativo sancionador, que el segundo deba ceder en favor de la continuación del primero. Por último, el propio sistema de fuentes nos da otro argumento en favor de la prevalencia penal, pues los tipos y las penas deben contenerse en una norma con rango de ley orgánica (necesidad de mayoría absoluta para su aprobación), mientras que en el derecho administrativo sancionador es suficiente que la norma tenga rango de ley y el papel del reglamento es, en muchas ocasiones, decisivo a la hora de determinar las infracciones ${ }^{16}$.

Sin embargo, el Tribunal Constitucional español no siempre ha defendido esta posición, sino que se inclinó durante unos años por un criterio puramente cronológico. Consideramos ilustrativo traer a colación la evolución del Alto Tribunal en esta materia.

En un primer momento, el Tribunal Constitucional se centró sobre todo en la vertiente procesal del non bis in idem y en la subordinación de la autoridad administrativa a la autoridad judicial, ambas ideas deducibles del principio de legalidad y tipicidad ${ }^{17}$. Trató de solucionar los problemas nacidos a la luz del principio non bis in idem desde un punto de vista competencial en favor del juez penal.

16 Cano Campos, Non bis..., 217-218.

17 Sentencia del Tribunal Constitucional español, rol $77 / 198_{3}$, 3 de octubre de $198_{3}$, fundamento jurídico 3 . 
Un giro a esta doctrina se produjo añadiendo el requisito cronológico al principio. Así, el Tribunal Constitucional advirtió que "el principio non bis in idem solo podrá invocarse en el caso de duplicidad de sanciones, frente al intento de sancionar de nuevo, desde la misma perspectiva de defensa social, unos hechos ya sancionados, o como medio para obtener la anulación de la sanción posterior" ${ }^{18}$. En definitiva, según esta doctrina jurisprudencial, en los supuestos de duplicidad de sanciones tendría preferencia la primera sobre la segunda.

Consideramos que ambos pronunciamientos son criticables con el mismo argumento: si bien trataban de solucionar el problema de la duplicidad de sanciones, no aportaban soluciones generales aplicables a todos los supuestos, pues no fundamentan la naturaleza de la prevalencia de la sanción penal sobre la administrativa ${ }^{19}$.

Esta carencia de fundamento de la primacía del orden penal sobre el administrativo acabó cuestionándose en la sentencia del Tribunal Constitucional español 177/1999²0, en la que continúa priorizándose el orden temporal de las sanciones y no su naturaleza penal o administrativa $^{21}$.

La toma de posición definitiva se produce mediante la sentencia del Tribunal Constitucional 2/2003, ya que devolvió la primacía del orden penal sobre la potestad sancionadora administrativa, considerando que en los "casos de concurrencia normativa aparente, de disposiciones penales y administrativas que tipifican infracciones, solo la infracción penal es realmente aplicable, lo que determina que el único poder público con competencia para ejercer la potestad sancionadora sea la jurisdicción penal" ${ }^{22}$. Como adelantamos al comienzo de este acápite, los argumentos fundamentales de la prevalencia penal sobre la potestad sancionadora de la Administración giran todos en torno a las mayores garantías del orden penal.

18 Sentencia del Tribunal Constitucional español, rol I59/1985, 27 de noviembre de ${ }_{9} 98_{5}$, fundamento jurídico 3 .

19 Sanz Rubiales, "Potestad...”, 559.

20 Sentencia del Tribunal Constitucional español, rol I77/I999, In de octubre de I999, fundamento jurídico 4: "Irrogada una sanción, sea esta de índole penal o administrativa, no cabe, sin vulnerar el mencionado derecho fundamental, superponer o adicionar otra distinta, siempre que concurran las tan repetidas identidades de sujetos, hechos y fundamento". Todo esto en el ámbito medioambiental, pues hubo una previa sanción administrativa y posterior penal por el vertido de sustancias contaminantes, y el Tribunal optó por anular la segunda y mantener la primera.

21 Gómez Tomillo y Sanz Rubiales, Derecho..., 215.

22 Sentencia del Tribunal Constitucional español, rol 2/2003, I6 de enero de 2003, fundamento jurídico 9 . 
Una vez aclarada la primacía del orden penal sobre el administrativo sancionador, trataremos de analizar situaciones que puedan surgir en la práctica y que podrían poner en jaque al principio non bis in idem.

\section{I. Procedimiento administrativo sancionador previo al proceso penal}

En primer lugar, aludiremos a los supuestos en que se sancionan unos hechos en vía administrativa y, luego, frente al mismo sujeto y con el mismo fundamento se sancionan en vía penal. En efecto, estos supuestos no deberían producirse, o no al menos tanto como se producen en la práctica, pues la Administración, cuando aprecia que los hechos constitutivos de infracción pueden serlo también de delito, tiene la obligación de suspender el procedimiento - o la ejecución de la sanción, si estuviera impuesta-. La realidad se antoja más compleja y nos obliga a solucionar precisamente estas hipótesis de sanción administrativa y después sanción penal ${ }^{23}$.

El Tribunal Constitucional español, en la citada sentencia 2/2003, optó por aplicar la "técnica del descuento". Esta técnica se traduce en la práctica en que, para no incurrir en la prohibición del bis in idem ${ }^{24}$, se proceda a descontar la sanción administrativa de la sanción penal impuesta y evitar así la duplicidad punitiva ${ }^{25}$. Esta parece una solución

23 Con la entrada en vigor de las leyes 39/20I5 y 40/20I5 (de Procedimiento Administrativo y de Régimen Jurídico del Sector Público, respectivamente) se derogó el reglamento del procedimiento para el ejercicio de la potestad sancionadora, y con él su artículo 7 , que obligaba "en cualquier momento del procedimiento sancionador en que los órganos competentes estimen que los hechos también pudieran ser constitutivos de ilícito penal, lo comunicarán al Ministerio Fiscal, solicitándole testimonio sobre las actuaciones practicadas respecto de la comunicación" y "recibida la comunicación, y si se estima que existe identidad de sujeto, hecho y fundamento entre la infracción administrativa y la infracción penal que pudiera corresponder, el órgano competente para la resolución del procedimiento acordará su suspensión hasta que recaiga resolución judicial”. Por lo tanto, la vertiente procesal del principio non bis in idem se ha excluido de la legislación básica administrativa, lo cual no quiere decir que no pueda exigirse, pues se deriva directamente de la eficacia directa del artículo 25 de la Constitución y la interpretación que de él hace el Tribunal Constitucional y de las numerosas leyes sectoriales que sí lo prevén de forma explícita.

24 La propia sentencia admite también la posibilidad de que pueda vulnerarse el principio cuando exista un procedimiento administrativo sancionador previo al penal, cuando el nivel de complejidad del procedimiento administrativo sancionador sea comparable a uno penal. En nuestra opinión, es complicado imaginar esta situación en la práctica.

25 Esta misma solución fue tomada ya por el Tribunal Europeo de Derechos Humanos, que en la sentencia del caso Oliveira con Suiza, rol 89/r998, 30 de julio de r998, p. 27, determinó que "no conlleva una falta de respeto del artículo 4 del protocolo 7 -relativo al non bis in idem-, cuando esta disposición no se opone a que jurisdicciones distintas conozcan delitos diferentes, siendo estos, elementos de un mismo hecho penal, y menos aún, cuando como en este caso, no ha habido acumulación de penas sino absorción de la más suave por la más dura”. 
satisfactoria mientras nos encontremos ante sanciones homogéneas - ambas pecuniarias, por ejemplo-. Sin embargo, resulta más difícil de aplicar cuando no exista homogeneidad entre las sanciones en juego. Aun con esta dificultad, desde un punto de vista práctico, esta solución puede resultar muy útili ${ }^{26}$.

A partir de esta sentencia, en los supuestos en que la Administración sanciona a un sujeto por unos hechos que, después, son enjuiciados y sancionados en un procedimiento penal, no se vulnera, en principio, la prohibición del bis in idem, siempre que, al imponer la pena, se tenga en cuenta la sanción administrativa para que la sanción resultante no sea desproporcionada ${ }^{27}$. Si no se aplicase esta "técnica del descuento", se produciría una duplicidad de sanciones y automáticamente la sanción administrativa debería declararse nula por vulnerar un derecho fundamental ${ }^{28}$. Esto es una muestra más de la primacía de la vertiente material del non bis in idem sobre la formal o procesal, puesto que esta última alcanza su máximo fundamento al servicio de la primera.

Solución distinta podría adoptarse si la sanción o la absolución administrativa está luego ratificada por la jurisdicción contencioso-administrativa, es decir, si la decisión del Poder Ejecutivo ha sido controlada por el Poder Judicial. En principio, si el juez contencioso-administrativo ratifica la sanción, la solución sería la misma que la que hemos explicado supra. Es decir, siempre y cuando esta sanción se tenga en cuenta por el juez penal para descontarla de la pena, no habría vulneración del non bis in idem.

Ahora bien, si el juez contencioso-administrativo absuelve al administrado -o bien porque convalida una previa absolución en vía administrativa, o bien porque anula una resolución sancionadora-, podría operar la intangibilidad de las resoluciones judiciales y, en consecuencia, el juez penal podría estar vinculado por la decisión del juez contencioso-administrativo. Si entendemos operativo el principio de intangibilidad de las resoluciones judiciales y el juez penal condena concurriendo la triple identidad, podría estar vulnerando el principio ${ }^{29}$.

26 En este sentido, Belén Marina Jalvo, "La problemática solución de la concurrencia de sanciones administrativas y penales: Nueva doctrina constitucional sobre el principio non bis in idem (Comentario de la zentencia del Tribunal Constitucional 2/2003, de 16 de enero)", Revista de Administración Pública I62 (2003): I88.

27 Pese a su utilidad práctica, no está exenta de críticas la "técnica del descuento". Gómez Tomi1lo, “Non bis...", ${ }_{43} 8$.

28 Gómez Tomillo y Sanz Rubiales, Derecho..., 220-22I.

29 Interesantísimo en este punto el análisis pormenorizado de la situación que lleva a cabo Gómez Tomillo, "Non bis...", 440-444. 
Consideramos que podría defenderse que no se vulnera el non bis in idem en estas circunstancias, pues las garantías del proceso penal siguen siendo superiores, aun cuando la resolución administrativa haya sido recurrida en vía contencioso-administrativa. Además, parece complicado hacer depender la validez de un proceso judicial penal del hecho de recurrir o no una sanción administrativa, puesto que, si no hay intervención judicial, no se pone en duda que el proceso penal no vulnera la prohibición del bis in idem.

\subsection{Procedimiento administrativo sancionador posterior al proceso penal}

Pasamos ahora a estudiar los supuestos contrarios, es decir, la posibilidad que tiene la Administración de perseguir unos hechos que puedan ser constitutivos de infracción administrativa, cuando esos mismos hechos frente al mismo sujeto ya han sido enjuiciados penalmente.

Entendemos necesario hacer una consideración previa antes de pasar a analizar la casuística que nos ofrece la práctica judicial. Una de las manifestaciones de la prevalencia penal frente al ámbito administrativo sancionador es la vinculación que tiene la Administración respecto de los hechos probados en vía penal ${ }^{30}$. De no admitirlo, podrían producirse situaciones en que unos mismos hechos existieron para un órgano del Estado y no existieron para otro, lo cual es del todo reprobable.

Dicho esto, analizaremos en primer lugar los casos en que la sentencia penal sea absolutoria y, posteriormente, aquellos en que concurra una sentencia penal previa condenatoria.

En principio, cuando el pronunciamiento judicial penal es absolutorio, parece que no existirá una vulneración del principio non bis in idem si la Administración decide iniciar un procedimiento administrativo sancionador contra la misma persona y por los mismos hechos. En efecto, cabe la posibilidad de que unos hechos no sean constitutivos de delito $y$, sin embargo, puedan encajar en la tipificación de una infracción administrativa ${ }^{31}$.

30 Idea que reproduce constantemente tanto la jurisprudencia (véase, por ejemplo, la sentencia del Tribunal Supremo, rol 8605/2006, Tercera Sala, II de septiembre de 2006, fundamento de derecho 3) como la legislación administrativa (artículo 77·4 de la Ley de Procedimiento Administrativo): "En los procedimientos de carácter sancionador, los hechos declarados probados por resoluciones judiciales penales firmes vincularán a las Administraciones Públicas respecto de los procedimientos sancionadores que substancien”.

31 Cano Campos, “Non bis...”, 225. 
Ahora bien, debemos matizar un poco. Si el pronunciamiento penal absolutorio consiste en un sobreseimiento libre que declara la inexistencia de los hechos o la no participación del sujeto investigado en esos hechos, no podríamos admitir el inicio de un procedimiento administrativo sancionador, pues, dada la vinculación de la Administración a los hechos probados en vía penal, se vulneraría el principio non bis in idem ${ }^{32}$.

Una segunda posibilidad la constituye el hecho de que el pronunciamiento judicial penal sea condenatorio. En principio, la sentencia penal condenatoria excluye la ulterior posibilidad de cualquier procedimiento administrativo sancionador sobre los mismos sujetos, hechos y fundamento, pues quedaría vulnerado el principio.

Cabría plantearse una excepción a esta regla general en aquellos supuestos en que la ley prevea una doble sanción material a unos mismos hechos. En estos casos, poco probables en la práctica, pero posibles, el principio de legalidad justificaría la doble sanción cuando concurra la triple identidad de hecho, sujeto y fundamento ${ }^{33}$. Dos serían los requisitos que deben converger para posibilitar la doble sanción: i) que la doble sanción material se encuentre expresamente prevista en la ley; y ii) que la suma de las dos sanciones no infrinja el principio de proporcionalidad, cuestión que requerirá un análisis del caso concreto ${ }^{34}$.

\section{EL ALCANCE DEL PRINCIPIO NON BIS IN IDEM EN EL ÁMBITO EXCLUSIVO DEL DERECHO ADMINISTRATIVO SANCIONADOR}

Si bien la problemática de la tramitación simultánea o sucesiva de un proceso penal y de un procedimiento administrativo sancionador -o la imposición de sanciones penales y administrativas - desde la óptica de la garantía fundamental del non bis in idem ha sido tratada masivamente por la doctrina científica, no ocurre lo mismo respecto del alcance del citado principio en el ámbito estrictamente administrativo.

32 Gómez Tomillo, “Non bis...”, $45^{\circ}$.

33 Así parece admitirlo también el artículo $5^{2 . I}$ de la Carta de los Derechos Fundamentales de la Unión Europea: "Cualquier limitación del ejercicio de los derechos y libertades reconocidos por la presente Carta deberá ser establecida por la ley y respetar el contenido esencial de dichos derechos y libertades. Solo se podrán introducir limitaciones, respetando el principio de proporcionalidad, cuando sean necesarias y respondan efectivamente a objetivos de interés general reconocidos por la Unión o a la necesidad de protección de los derechos y libertades de los demás”. Sentencias del Tribunal de Justicia de la Unión Europea, rol 59/20r8 (Gran Sala), rol 6r/20I8 (Gran Sala) y rol 60/20I8 (Gran Sala), todas del 20 de marzo de 2018.

34 Gómez Tomillo, "Non bis...", 445. Admitiendo la posibilidad de doble sanción material, reconoce el autor la dificultad de encontrarse con un caso en la práctica que cumpla los requisitos de proporcionalidad y doble sanción prevista expresamente en la ley. 
Desde el punto de vista material, de lo que se trata es de evitar el doble castigo administrativo a un mismo sujeto, por unos mismos hechos y con idéntico fundamento. No es una situación extraña en la práctica que existan dos normas administrativas potencialmente aplicables al caso concreto. En efecto, aplicar ambas supondría vulnerar el derecho fundamental que ahora analizamos. Por ello, la doctrina opta por aplicar las reglas elaboradas por la dogmática jurídico-penal para inclinarse por una y otra norma ${ }^{35}$ :

- Principio de especialidad: La norma especial deroga la norma general.

- Principio de subsidiariedad: La norma principal se aplica preferentemente a la norma subsidiaria.

- Principio de consunción: La norma sancionadora más amplia o compleja absorbe las normas sancionadoras que castiguen infracciones consumidas en aquella.

- Principio de alternatividad: En defecto de los criterios anteriores, la norma administrativa sancionadora más grave excluirá las que castiguen la misma infracción con una sanción menor.

Por último, en lo que respecta a los concursos de infracciones, consideramos que no son supuestos que entren en contradicción con el principio ${ }^{36}$, pues ni en el concurso real ni en el ideal concurre la triple identidad necesaria para vulnerarlo. Por un lado, en el concurso real no hay identidad de hechos, pues se valoran acciones $u$ omisiones que dan lugar a diversas infracciones y, por otro lado, en el concurso ideal - en el que una única conducta produce varias infracciones-, cada infracción tiene como finalidad proteger un bien jurídico distinto.

A continuación, trataremos de abordar esta problemática desde el punto de vista procedimental. Es decir, analizaremos la posibilidad de compatibilizar o no con el principio non bis in idem la existencia de procedimientos administradores sancionadores simultáneos o sucesivos concurriendo la triple identidad (sujeto, hecho y fundamento).

\section{I. La concurrencia de procedimientos administrativos sancionadores}

Sin duda, se produce una vulneración de la vertiente procedimental del principio non bis in idem cuando la Administración Pública tramita dos procedimientos sancionadores en simultáneo frente al mismo sujeto, por los mismos hechos y bajo el mismo fundamento.

35 Rosa Fernanda Gómez González, "El non bis in idem en el derecho administrativo sancionador: Revisión de sus alcances en la jurisprudencia administrativa”, Revista de Derecho de la Pontificia Universidad Católica de Valparaíso 49 (20I7): I2I-I22.

36 Lucía Alarcón Sotomayor, "Principio non bis in idem", en Diccionario de sanciones administrativas, dir. por Blanca Lozano (Madrid: Iustel, 20I0), 769-770. 
Como venimos defendiendo, la citada vertiente procedimental del principio está al servicio de la vertiente material. Es decir, la garantía última de este principio implica impedir la doble sanción. Sin perder de vista esta idea, no debemos olvidar que la situación perfecta pasaría por evitar la concurrencia de procedimientos administrativos sancionadores, pero la práctica nos demuestra que esta situación puede producirse.

Dicho lo cual, para tratar de impedir la vulneración de esta vertiente procedimental del non bis in idem, la Administración debería de oficio poner fin a estas situaciones aplicando las reglas relativas a los conflictos de competencia. Si la Administración no actúa en este sentido, el administrado podrá, en cualquier caso, poner en su conocimiento esta situación, para tratar de evitar el doble procedimiento ${ }^{37}$.

Por último, debemos advertir que esta situación, aunque posible, no es muy frecuente en la práctica. En principio, si es la misma Administración la que inicia ambos procedimientos, lo lógico es que uno de ellos acabe archivándose y, si son distintas Administraciones, lo normal será que ambas respuestas sancionadoras respondan a fundamentos distintos evitando el bis in idem. Si el fundamento fuera el mismo, como hemos aclarado más arriba, serán las normas relativas a los conflictos de competencia las que deban evitar el doble procedimiento.

\subsection{La tramitación sucesiva de procedimientos administrativos sancionadores: Especial referencia a la terminación del primero por caducidad}

Es lugar común en la doctrina que la garantía del non bis in idem prohíbe iniciar a la Administración un nuevo procedimiento sancionador cuando existe una resolución firme sobre el fondo respecto al mismo sujeto, hecho y fundamento, independiente de que esa resolución sea sancionadora o absolutoria ${ }^{38}$. Admitir lo contrario supondría, en efecto, una disminución injustificada de la seguridad jurídica ${ }^{39}$ para el administrado, que ya se enfrentó una vez a la potestad sancionadora de la Administración por esa misma conducta.

Como vimos más arriba, existe una prevalencia de la jurisdicción penal sobre la potestad sancionadora administrativa, que justifica la posibilidad de abrir un proceso penal después de un procedimiento administrativo sancionador - siempre que tenga en cuenta la sanción impuesta por la Administración a la hora de imponer la cuantía de la pena-. Sin embargo, dentro de las Administraciones Públicas no parece que pueda predicarse la prevalencia de una sobre otra en materia sancionadora. Por ello, consideramos útil en

\footnotetext{
37 Cano Campos, “Non bis...”, 240.

38 Gómez González, "El non bis...", I22.

39 Cano Campos, “Non bis...”, 24,
} 
estos casos la aplicación del criterio cronológico, de forma que la Administración que complete un procedimiento sancionador cerrará la puerta a la posibilidad de que otra Administración distinta, o ella misma, abra un nuevo procedimiento en que concurra la triple identidad.

Ahora bien, existen posiciones encontradas en la doctrina sobre si constituye o no vulneración del non bis in idem el hecho de abrir un segundo procedimiento administrativo sancionador cuando el primero ha terminado sin resolución sobre el fondo del asunto, en especial en los supuestos de caducidad.

Parte de la doctrina considera que no puede ser válida una sanción administrativa impuesta en un segundo procedimiento administrativo cuando el primero haya terminado por caducidad, pues se produciría una vulneración inequívoca de la vertiente formal del derecho fundamental al non bis in idem ${ }^{40}$, junto con una situación de pendencia jurídica del todo contraria a la seguridad jurídica ${ }^{41}$. Además, considera este sector doctrinal que de nada serviría el instituto jurídico de la caducidad de los procedimientos sancionadores si la Administración puede volver a abrir en forma indefinida un procedimiento sancionador.

Pues bien, en coherencia con el alcance que venimos defendiendo del principio non bis in idem, consideramos oportuno diferenciar dos situaciones.

En primer lugar, consideramos contrario al non bis in idem el hecho de que la Administración dicte una resolución sancionadora cuando el procedimiento administrativo esté ya caducado para después, anulada o revocada esta sanción dictada con el procedimiento caducado, volver a sancionar en un nuevo procedimiento. Consideramos que se ha consumado una doble sanción, aunque la primera fuera dictada con el procedimiento caducado, pues el administrado ha tenido que soportar de facto la doble sanción, sumado a una situación de absoluta inseguridad jurídica y desproporción.

Valoración diferente nos merece el hecho de que el procedimiento caducado haya terminado sin resolución sobre el fondo y, con posterioridad, un nuevo procedimiento haya concluido con una resolución sancionadora. En estos casos, no existe una vulneración de la vertiente material del non bis in idem. No podemos olvidar que la garantía última del principio es impedir la doble sanción y que la vertiente procedimental cobra sentido, no tanto de forma independiente, sino al servicio de que no se consume una vulneración material.

40 Cano Campos, “Non bis...", 224. También, entre la doctrina chilena, Gómez González, "El non bis...", I23.

41 Gabriel Doménech Pascual, "Principio non bis in idem y reapertura de procedimientos sancionadores caducados", en Diccionario de Sanciones Administrativas, dir. por Blanca Lozano (Madrid: Iustel, 2010), 784 . 
Además, el propio legislador reconoce de manera implícita esta posibilidad, pues considera, en el artículo 95.3 de la Ley de Procedimiento Administrativo española que "la caducidad no producirá por sí sola la prescripción de las acciones del particular o de la Administración, pero los procedimientos caducados no interrumpirán el plazo de prescripción”. Consideramos, en efecto, que es una situación poco deseable, pues existe una disminución de garantías para el administrado, pero no suficiente como para producir la vulneración del derecho fundamental al non bis in idem, pues no se consuma la doble sanción.

\section{CONCLUSIONES}

Una de las consecuencias lógicas de la idéntica naturaleza jurídica del ius puniendi estatal es la aplicación "con matices" de los principios inspiradores del orden penal a la actividad sancionadora de la Administración. Uno de estos principios, con rango de derecho fundamental, es la prohibición del bis in idem.

En relación con el contenido de este principio, coincide la doctrina en destacar dos manifestaciones: por un lado, la vertiente material, que proscribe la doble sanción cuando concurran los mismos hechos, sujeto y fundamento; y, por otro lado, la vertiente procedimental, que prohíbe la existencia de dos procedimientos punitivos simultáneos o sucesivos concurriendo también la triple identidad. En efecto, la vulneración definitiva del principio non bis in idem pasa por la existencia de una doble punición material, por lo que su vertiente procedimental cobra sentido en la medida que evite una duplicidad real de sanciones.

El principio non bis in idem se fundamenta en el principio de legalidad, en concreto, en la exigencia de lex certa o principio de tipicidad, según el cual el legislador deberá identificar de manera suficiente en la norma las conductas constitutivas de infracción. En consecuencia, la perfecta identificación de las conductas hará que estas sean excluyentes, es decir, una vez sancionada una acción u omisión, el Estado no puede volver a sancionarla. No podemos discutir que principios como la seguridad jurídica o la proporcionalidad se podrían ver conculcados con una vulneración del principio non bis in idem; sin embargo, no pueden servirle de fundamento.

Reconocer la idéntica naturaleza del ius puniendi del Estado no impide afirmar la prevalencia de la jurisdicción penal frente a la potestad sancionadora de la Administración. Una prevalencia que se basa, fundamentalmente, en las mayores garantías del proceso penal frente al administrativo sancionador, en la condición de ultima ratio que tiene el derecho penal en los sistemas jurídicos e, incluso, en principio democrático que exige unas mayorías más cualificadas para las leyes que tipifiquen delitos (ley orgánica), que para aquellas que describan infracciones administrativas (ley ordinaria). 
Precisamente por esta prevalencia del orden penal, no se considera vulnerado el non bis in idem cuando, después de un procedimiento administrativo sancionador, se abra un proceso penal, siempre y cuando, a la hora de la imposición de la pena, el juez "descuente" la sanción administrativa antes impuesta. Más problemas plantearía el hecho de que la jurisdicción contencioso-administrativa absuelva al administrado, pues en estos casos entra en juego el principio de intangibilidad de las resoluciones judiciales.

Otra manifestación de la primacía del orden penal es la vinculación de los hechos probados declarados en una sentencia penal a un posible procedimiento administrativo sancionador posterior. De este modo, la Administración solo verá vetada su posibilidad de sancionar cuando en la sentencia absolutoria o auto de sobreseimiento se declare la inexistencia de los hechos que constituyen la infracción administrativa o la no participación del administrado en ellos. Incluso podría sancionar después de una sentencia penal condenatoria si una disposición con rango de ley lo establece en forma expresa, cuestión difícil de plantearse en la práctica, pues lo normal es que, si esto ocurre, el fundamento de las sanciones sea diverso.

El derecho administrativo sancionador considerado de manera individual tampoco está exento de situaciones analizables a la luz del principio non bis in idem. En efecto, desde el punto de vista material puede ocurrir que una conducta sea subsumible en varias infracciones administrativas. En este caso, para determinar qué norma es aplicable y evitar así la doble sanción, habrá que acudir a la aplicación de los principios de especialidad, subsidiariedad, consunción y alternatividad ampliamente desarrollados por la dogmática jurídico-penal.

Desde el punto de vista procedimental, pocas dudas existen en que no se debe permitir la existencia de dos o más procedimientos administrativos sancionadores simultáneos. Habrá que acudir a las normas que regulan los conflictos de competencia entre las distintas administraciones para evitar una posible doble sanción administrativa.

En relación con los procedimientos sancionadores sucesivos, dictada la resolución sobre el fondo del asunto por una administración — sea sancionadora o absolutoria-, se cierra la puerta a la posibilidad de abrir un nuevo procedimiento administrativo sancionador con idéntico objeto, sujeto y fundamento. Cuestión diferente se produce cuando el primer procedimiento administrativo termina sin un pronunciamiento sobre el fondo, por ejemplo, por caducidad. Consideramos que, dada la primacía de la vertiente material del principio non bis in idem a la hora de valorar su vulneración, debe permitirse un segundo procedimiento administrativo - siempre que la infracción no haya prescrito-, pues en ningún caso podría producirse una doble sanción. 


\section{BIBLIOGRAFÍA}

- Alarcón Sotomayor, Lucía. "Principio non bis in idem”. En Diccionario de sanciones administrativas, dirigido por Blanca Lozano. Madrid: Iustel, 2010.

- Boto Álvarez, Alejandra. "Actos administrativos que lesionan derechos y libertades susceptibles de amparo constitucional: Análisis de la doctrina de los órganos consultivos en expedientes de revisión de oficio". Revista Vasca de Administración Pública 96 (2013): 19-72. https://dialnet.unirioja.es/servlet/articulo? codigo $=4565013$.

- Cano Campos, Tomás. "Non bis in idem, prevalencia de la vía penal y teoría de los concursos en el derecho administrativo sancionador". Revista de Administración Pública 156 (2001): 191-250. https://dialnet. unirioja.es/servlet/articulo?codigo $=17556$.

- Cubero Marcos, José Ignacio. El principio non bis in idem en la ley vasca de la potestad sancionadora. Oñate: Instituto Vasco de Administración Pública, 2010.

- Doménech Pascual, Gabriel. "Principio non bis in idem y reapertura de procedimientos sancionadores caducados". En Diccionario de sanciones administrativas, dirigido por Blanca Lozano. Madrid: Iustel, 2010.

- Gómez González, Rosa Fernanda. "El non bis in idem en el derecho administrativo sancionador: Revisión de sus alcances en la jurisprudencia administrativa”. Revista de Derecho de la Pontificia Universidad Católica de Valparaíso 49 (2017): 101-138. doi: 10.4067/S071868512017000200101

- Gómez Tomillo, Manuel. "Non bis in idem en los casos de dualidad de procedimientos penal y administrativo: Especial consideración de la jurisprudencia del TEDH". InDret 3 (2020): 421-456. https:// indret.com/non-bis-in-idem-en-los-casos-de-dualidad-de-procedimientos-penal-y-administrativo-especial-consideracion-de-la-jurisprudencia-del-tedh/.

- Gómez Tomillo, Manuel e Íñigo Sanz Rubiales. Derecho administrativo sancionador: Parte general. Cizur Menor: Aranzadi, 2017.

- Mañalich, Juan Pablo. "El principio ne bis in idem frente a la superposición del derecho penal y el derecho administrativo sancionatorio". Política Criminal 9, n. ${ }^{\circ} 18$ (2014). doi: 10.4067/S071833992014000200008. 
- Marín de Espinosa Ceballos, Elena Blanca. "El principio non bis in idem: La acumulación de sanciones penales y administrativas en la protección del medio ambiente". En Derecho, globalización, riesgo y medio ambiente, editado por Esteban Juan Pérez Alonso, Estanislao Arana García, Pedro Mercado Pacheco y José Luis Serrano Moreno. Valencia: Tirant lo Blanch, 2012.

- Marina Jalvo, Belén. "La problemática solución de la concurrencia de sanciones administrativas y penales: Nueva doctrina constitucional sobre el principio non bis in idem (Comentario de la sentencia del Tribunal Constitucional 2/2003, de 16 de enero)". Revista de Administración Pública 162 (2003):175-188. https://dialnet.unirioja.es/servlet/ articulo? codigo $=784928$.

- Ossandón Widow, María Magdalena. "El principio ne bis in idem en el sistema jurídico chileno: Análisis de la jurisprudencia constitucional". Revista de Ciencias Penales 42 (2016). doi: 10.4067/S071833992018000200952.

- Sanz Rubiales, Íñigo. "Potestad sancionadora administrativa, non bis in idem y primacía del orden penal (Comentarios a la STC 177/1999, de 11 de octubre)". Revista del Poder Judicial 59 (2000): 545-572. https:// dialnet.unirioja.es/servlet/articulo?codigo $=198121$. 